\title{
Animal-assisted Therapy for the Emotional Well-being of Children with Intellectual Disabilities and Behavioral Disorders
}

\author{
Maylos Rodrigo-Claverol ${ }^{1,2, *}$, Belén Malla-Clua ${ }^{1}$, Esther Rodrigo-Claverol ${ }^{3}$, Júlia Jové-Naval ${ }^{1,4}$, \\ Jèssica Bergadà-Bell-lloc ${ }^{4}$, Josep Ramon Marsal-Mora ${ }^{5,6}$ \\ ${ }^{1}$ Primary Health Care Center Bordeta-Magraners, Catalan Institute of Health, Lleida, Spain \\ ${ }^{2}$ Nursing and Physiotherapy Faculty, University of Lleida, Lleida, Spain \\ ${ }^{3}$ Primary Health Care Center Primer de Maig, Catalan Institute of Health, Lleida, Spain \\ ${ }^{4}$ Ilerkan Association, Lleida, Spain \\ ${ }^{5}$ Research Support Unit, IDIAP Jordi Gol, Lleida, Spain \\ ${ }^{6}$ Epidemiology Unit of the Cardiology Service, Vall d'Hebron University Hospital, Barcelona, Spain
}

Copyright $\odot 2018$ by authors, all rights reserved. Authors agree that this article remains permanently open access under the terms of the Creative Commons Attribution License 4.0 International License

\begin{abstract}
Studies conducted in educational settings show that animals attract and maintain the attention of children. The calming effects of animals are especially valuable in children with attention deficit, hyperactivity and behavioral disorders. The primary goal was to improve the emotional well-being, in a special education school, of children with intellectual disabilities, attention problems and/or hyperactivity and behavioral disorders. A Longitudinal, Observational Study was designed, which consisted of a community intervention based on animal-assisted therapy (AAT), and performed at a Primary Care Center (PCC). Twelve weekly group sessions were held with therapy dogs; a nurse and a doctor from the PCC participated with training in AAT as well as teachers. The intervention was carried out in two classrooms at the school. The sample size was 12 children with an average age of $12.7(\mathrm{SD} \pm 4.4)$ years. Variables studied: attention, happiness, relaxed, respect of turn. The overall improvement of the four variables was statistically significant $(\mathrm{p}<0.001)$, evolving in an ascending and progressive way. Throughout the sessions, a work dynamic was achieved with improved attention and respect of turns; happiness and relaxation that reflect emotional well-being remain at high levels, with the dog acting as a facilitator of the therapy. Primary Health Care can contribute to improving the quality of life of children with special needs and at risk of social exclusion by means of community interventions.
\end{abstract}

Keywords Animal-assisted Therapy, Primary Health Care Center, Community Intervention, Intellectual Disability, Emotional Wellbeing, School

\section{Introduction}

Primary Health Care is the first level of access to public health care. It is comprised of interdisciplinary teams of professionals from Family Medicine, Pediatrics, Dentistry, Nursing, Nursing Assistants, Social Workers and patient care professionals. These teams work with the objective of offering the highest quality health care, placing citizens at the heart of the health care process, taking care of their health throughout the vital process. In addition to the diagnosis, treatment and monitoring of health problems, these teams work for disease prevention, health promotion and health education, offering health and social care [1].

Community interventions are actions aimed at groups or collectives of people, which can be carried out jointly or otherwise with other services and with the same implicated group that has a common need and are oriented to improving their health [2]. This project is a community intervention that was carried out in a Special Education School in order to promote the health of children with special educational needs by improving emotional well-being.

The success of a school that promotes health depends, in part, on its interaction with other elements of the community such as the Primary Care Center. A health promoting school is one that offers optimal circumstances for the emotional, intellectual, physical and social development of students. The aim is to promote, encourage and enable the acquisition of personal and social skills aimed at creating positive values and attitudes towards health, based on their own capacity for decision-making, participation and equality, according to the intellectual, 
physical and mental health development of the child. The role of teachers is to favor and enable the development of these skills [3]. Education centers, as learning spaces, the education and the integral training of a person, are also places where the early signs of health problems are presented, in which early detection may be the first action to initiate a process of helping the needs, often not expressed, but manifested through behavior.

Studies conducted in educational settings show that animals attract and maintain the attention of children. It seems that the calming effects of animals are especially valuable in children with attention deficit, hyperactivity and behavioral disorders [4].

Since 2008 at the Bordeta-Magraners Primary Care Center belonging to the Catalan Health Institute, community intervention projects are being carried out by means of animal-assisted therapy.

Animal Assisted Interventions (AAI) encompasses different interactions between people and animals and is classified according to the professionals who are involved in the design, development and evaluation [5]. In our case, despite being carried out in a Special Education Center with the collaboration of the professionals of the center, it is not considered an Assisted Education with Animals Project since we did not work curricular objectives. The aim was an Animal-Assisted Therapy Project directed by health care professionals at the Primary Attention Center with the objective of emotional well-being. PCC professionals went to the school to conduct the sessions.

The International Association of Human-Animal Interaction Organizations (IAHAIO) [6] defines Animal-Assisted Therapy as a planned, structured, documented, objective-directed therapeutic intervention led by health professionals or social services as part of their profession. A wide variety of disciplines can incorporate it, such as: medicine, occupational therapy, physiotherapy, nursing, social work, speech therapy or mental health professionals. These are not alternative therapies; they are complementary programs where the animal is a motivating and facilitating element of the therapy.

Animal-Assisted Therapy is an innovative resource for the management of situations of functional dependence, psychiatric disorders, behavioral and attention disorders in people with disabilities and special educational needs [7].

Animal-assisted interventions are based on the link that is generated between the human and the therapy animal; in fact, it has been seen that children with a pet expressed their emotions, sought social support and used problem solving more than children without pets. In addition, the presence of animals tends to reduce aggression in children and increase patience and behavior control. One possible explanation is that the animal does not judge and therefore, children do not feel any associated pressure [8].
Martínez Abellán [7] summarizes the benefits of Animal-Assisted Intervention programs in children and adolescents in: stimulation for psychomotor and language development, improvement of non-verbal communication, increased social competence and self-esteem, positivism, favoring symbolic play and responsibility. It also points to the fact that animals used in educational and therapeutic interventions have a great influence on cooperative work and therapeutic change. The essence of AAI consists of introducing a non-threatening animal to become a catalyst, forming adaptable and satisfying social relationships. The animal becomes a point in common in the interaction between the child and the adult during the work with the professionals.

In a study by Kotrschal and Ortbauer [9], students paid more attention to their teachers and showed less aggressive and hyperactive behaviors when a dog was present in the classroom. In the same vein, Hergovich et al. [10] found that students, in addition to being less aggressive, had more empathy when a dog was present. And Gee, Harris and Johnson [8] conducted their study with a group of 14 children with language problems completing tasks more quickly without compromising accuracy, with the dog acting as a motivating element for the child.

In Jalongo's study [11] the attention and motivation of students improved when animals were used in the classroom. In the course of his research, Gee et al. [12] found that a special bond is created between animals and children which contributes to healthy learning, saying that "these effects are the result of increased attention and/or motivation resulting from the presence of the dog." Beck and Katcher [13] stated that "animals can induce a state of immediate relaxation, psychologically reassuring, simply by attracting and holding our attention." Evidence suggests that a dog in the classroom can have beneficial effects in a series of behavioral processes that contribute to a positive effect on the environment, which translates into better performance by children [14].

In a study evaluating parents' opinion of AAT as a complementary treatment for children with behavioral problems; $81 \%$ of parents considered AAT to be a highly acceptable treatment, indicating a positive attitude toward this form of treatment of mental health problems in children [15].

Findings in revised literature motivated the realization of this study from Primary Care and carried out in a Special Education Center with children with behavioral disorders, which we call "My Friend from the Primary Healthcare Center: the Therapy Dog".

The main objective was to improve the emotional well-being of the children who participated in the study; by means of: Improving levels of attention and concentration, improving self-control and relaxation, promoting a cheerful mood and respecting the waiting turns during the activity. 


\section{Materials and Methods}

\subsection{Design}

A Longitudinal, Observational Study was designed; which consisted of a community intervention, performed at an urban Primary Care Center (PCC).

\subsection{Participants}

The study included 12 children $(6(50 \%)$ boys and 6 $(50 \%)$ girls $)$ with an average age of $12.7(\mathrm{SD} \pm 4.4)$ years (Table 1) and that attended a special education school in the neighborhood. Inclusion criteria: children with intellectual disabilities, attention problems and/or hyperactivity and behavioral disorders. No allergy or phobia of dogs (information requested from parents prior to inclusion in the study).

Table 1. Age and sex description

\begin{tabular}{|c|c|c|c|}
\hline \multicolumn{2}{|c|}{} & N & n (\%) \\
\hline Gender & $\mathrm{n}(\%)$ & 12 & \\
\hline Male & & & $6(50 \%)$ \\
\hline Women & & & $6(50 \%)$ \\
\hline Age (years) & mean \pm SD & 12 & $12.7 \pm 4.4$ \\
\hline
\end{tabular}

The staff who participated in the sessions was as follows: a PCC nurse with training in AAI, a PCC physician with training in AAI and that in the sessions acted as a coach directing the interaction of children with the dogs. And the teachers of the children also collaborated in the planning of the sessions. The PCC doctor was responsible for designing and coordinating the study, performing the analysis of the results and the scientific dissemination of the results. During the AAT sessions he acted as a technician in AAI with the therapy dogs.

Therapy animals: Two dogs (a 4-year-old Golden Retriever male and a 2-year-old Cavalier King Charles female) participated. Both dogs were trained and accredited as therapy dogs and had spent time working on different AAI projects. They had civil liability insurance and periodic and analytical veterinary controls for the prevention of zoonoses.

Dogs play an important role in AAT [16], in a review of 25 articles from empirical studies with children and adolescents in schools, three types of animals were used: Guinea pigs were used in 3 studies, 1 rabbit participated and in the remaining 21 they included a dog [17].

We decided to work with dogs because they are sociable animals that seek interaction with people, they are integrated into society and they contribute multisensory stimuli.

In other studies, involving live animals in classrooms, they reported the drawbacks of having animals living in the classroom such as responsibility, maintenance cost, zoonotic diseases, allergies, concern for the general welfare of the animal and the children [18]; which is why they had relatively easy to maintain species like fish and turtles. To avoid such inconveniences and to ensure the well-being of the dogs, we decided to work with accredited therapy dogs that were brought to the school only to perform the sessions.

\subsection{Variables}

\section{Age and Gender}

Likert Rating Continuous Scale that values with gradation from 0 to $3(0=$ never, $1=$ sometimes, $2=$ often and 3 = always) the following items: attention, happiness, relaxed, respect turn. It was passed at the end of these specific sessions: 1 (baseline), session 3, session 5, session 8, session 10 and session 12 (end).

The observation and assessment of the sessions was carried out by the nurse who was present at all sessions. We considered:

Attention: keep eye contact with professionals, colleagues and/or dog. Behaviors indicate interest in the activity, object or situation. Nod or verbalizations related to the activity.

Happiness: present behaviors that indicate pleasure such as smiling or laughing, vocalizations or verbalizations of pleasure, applauding, showing intentionality towards contact with the animal.

Relaxed: it was considered that the participant was relaxed when he or she touched and gently stroked the dog. If he or she did not scream, did not cry, did not run, did not jump and did not throw objects.

Respect turn: Follow the instructions requested to carry out the proposed tasks. Share or deliver objects when requested. Do not interrupt when it is another participant's and do not alter the dynamics of the sessions.

\subsection{Intervention}

There were 12 group sessions with the participation of 6 children per group. The duration of each session was 60 minutes, carried out weekly from November to February. The intervention was carried out at the school premises, the two sessions being held the same day and in two different classrooms at the school. Being a community intervention, the PCC professionals were the ones who went to the school to carry out the sessions.

The sessions were previously planned by the professionals who participated in the study. They all had a home routine where children would greet and pet the therapy dogs and fetch water. A development of the session where every day has different exercises were performed and a finishing routine where the children brushed and caressed the dogs again (Appendix 1). 
During the course of the sessions, the two therapy dogs took part, which served as an example when it came to respecting the shifts. Throughout the sessions tasks were carried out for recognizing, pairing or categorizing objects or images, classifying colors and shapes, arranging sizes and exercises of psicomotricidad. The therapy dog served as an intermediary and the professionals could check the child's understanding by asking him or her to explain the task to the dog.

\subsection{Data Analysis}

The Attention, happiness, relaxation and respect for the turn variables were described using the calculation of absolute and relative frequencies, as well as the mean and standard deviation in each of the visits specified. We tested if there were differences in the baseline assessment in each of the visits, using the non-parametric test of Friedman. In parallel, we also estimated the improvement, as the difference between each assessment and the baseline divided by the baseline assessment. The SPSS statistical package was used.

\subsection{Ethical Considerations}

We requested from the parents or legal guardian a signature of authorization to participate in the sessions and the consent for the registration of image for educational and scientific purposes.

The personal data of the children are confidential and used only for this research, according to the organic law of protection of personal data 15/99 (LOPD).

We ensured at all times the well-being, both physical and mental, of the animal during the sessions, as well as maintain appropriate sanitary conditions. In this sense, children were taught how to be respectful of the dog, how to pet it and how to satisfy its needs; and the technician always supervised the interaction. At no time was there any manifestation of aggression directed towards the animal.

\section{Results}

The results obtained in the variable Attention (Table 2) in session 1 (baseline) were: 0 in $58 \%$ of the participants, 1 in $33.3 \%, 2$ in $8.3 \%$ and 3 in $0 \%$ of the participants. In session 12 (final): 0 in $0 \%$ of the participants, 1 in $25 \%, 2$ in $25 \%$ and 3 in $50 \%$ of the participants.

Table 2. Attention variable results

\begin{tabular}{|c|c|c|c|c|c|c|}
\hline & S1 & S3 & S5 & S8 & S10 & S12 \\
\hline & $\mathrm{n}=12$ & $\mathrm{n}=12$ & $\mathrm{n}=12$ & $\mathrm{n}=12$ & $\mathrm{n}=12$ & $\mathrm{n}=12$ \\
\hline 0 & $7(58.3 \%)$ & $3(25 \%)$ & $1(8.3 \%)$ & $0(0 \%)$ & $0(0 \%)$ & $0(0 \%)$ \\
\hline 1 & $4(33.3 \%)$ & $7(58.3 \%)$ & $6(50 \%)$ & $4(33.3 \%)$ & $3(25 \%)$ & $3(25 \%)$ \\
\hline 2 & $1(8.3 \%)$ & $2(16.7 \%)$ & $4(33.3 \%)$ & $6(50 \%)$ & $3(25 \%)$ & $3(25 \%)$ \\
\hline 3 & $0(\%)$ & $0(\%)$ & $1(8.3 \%)$ & $2(16.7 \%)$ & $6(50 \%)$ & $6(50 \%)$ \\
\hline
\end{tabular}

In the variable Happiness (Table 3 ) the results in session 1 were 0 in $25 \%$ of participants, 1 in $50 \%, 2$ in $25 \%$ and 3 in $0 \%$ of participants. And in session 12 (final): 0 in $0 \%, 1$ in $16.7 \%, 2$ in $25 \%$ and 3 in $58.3 \%$ of the participants.

Table 3. Happiness variable results

\begin{tabular}{|c|c|c|c|c|c|c|}
\hline & S1 & S3 & S5 & S8 & S10 & S12 \\
\hline & $\mathrm{n}=12$ & $\mathrm{n}=12$ & $\mathrm{n}=12$ & $\mathrm{n}=12$ & $\mathrm{n}=12$ & $\mathrm{n}=12$ \\
\hline 0 & $3(25 \%)$ & $3(25 \%)$ & $2(16.7 \%)$ & $1(8.3 \%)$ & $0(0 \%)$ & $0(0 \%)$ \\
\hline 1 & $6(50 \%)$ & $3(25 \%)$ & $2(16.7 \%)$ & $2(16.7 \%)$ & $2(16.7 \%)$ & $2(16.7 \%)$ \\
\hline 2 & $3(25 \%)$ & $5(41.7 \%)$ & $7(58.3 \%)$ & $6(50 \%)$ & $4(33.3 \%)$ & $3(25 \%)$ \\
\hline 3 & $0(\%)$ & $1(8.3 \%)$ & $1(8.3 \%)$ & $3(25 \%)$ & $6(50 \%)$ & $7(58.3 \%)$ \\
\hline
\end{tabular}

Regarding the variable Relaxation (Table 4) we observed in the first session: 0 in $8.3 \%, 1$ in $58.3 \%, 2$ in $25 \%$ and 3 in $8.3 \%$ of the participants. Session $12: 0$ in $0 \%, 1$ in $0 \%, 2$ in $33.3 \%$ and 3 in $66.7 \%$ of the participants.

Table 4. Relaxation results

\begin{tabular}{|c|c|c|c|c|c|c|}
\hline & S1 & S3 & S5 & S8 & S10 & S12 \\
\hline & $\mathrm{n}=12$ & $\mathrm{n}=12$ & $\mathrm{n}=12$ & $\mathrm{n}=12$ & $\mathrm{n}=12$ & $\mathrm{n}=12$ \\
\hline 0 & $1(8.3 \%)$ & $1(8.3 \%)$ & $1(8.3 \%)$ & $0(0 \%)$ & $0(0 \%)$ & $0(0 \%)$ \\
\hline 1 & $7(58.3 \%)$ & $6(50 \%)$ & $2(16.7 \%)$ & $1(8.3 \%)$ & $1(8.3 \%)$ & $0(0 \%)$ \\
\hline 2 & $3(25 \%)$ & $4(33.3 \%)$ & $7(58.3 \%)$ & $9(75 \%)$ & $4(33.3 \%)$ & $4(33.3 \%)$ \\
\hline 3 & $1(8.3 \%)$ & $1(8.3 \%)$ & $2(16.7 \%)$ & $2(16.7 \%)$ & $7(58.3 \%)$ & $8(66.7 \%)$ \\
\hline
\end{tabular}


Finally, in variable Respect turn (Table 5) in session 1 the results were: 0 in 100\% of participants and in session 12 (final): 2 in $16.7 \%$ and 3 in $83.3 \%$.

Table 5. Respect waiting time results

\begin{tabular}{|c|c|c|c|c|c|c|}
\hline & S1 & S3 & S5 & S8 & S10 & S12 \\
\hline & $\mathrm{n}=12$ & $\mathrm{n}=12$ & $\mathrm{n}=12$ & $\mathrm{n}=12$ & $\mathrm{n}=12$ & $\mathrm{n}=12$ \\
\hline 0 & $12(100 \%)$ & $3(25 \%)$ & $0(0 \%)$ & $0(0 \%)$ & $0(0 \%)$ & $0(0 \%)$ \\
\hline 1 & $0(0 \%)$ & $9(75 \%)$ & $3(25 \%)$ & $0(0 \%)$ & $0(0 \%)$ & $0(0 \%)$ \\
\hline 2 & $0(0 \%)$ & $0(0 \%)$ & $6(50 \%)$ & $5(41.7 \%)$ & $3(25 \%)$ & $2(16.7 \%)$ \\
\hline 3 & $0(0 \%)$ & $0(0 \%)$ & $3(25 \%)$ & $7(58.3 \%)$ & $9(75 \%)$ & $10(83.3 \%)$ \\
\hline
\end{tabular}

In Tables 2, 3, 4 and 5 it is possible to observe how session after session that 0 is less visible and 3, more and more.

The score of each variable in each of the sessions in numerical form is reflected in Table 6; where p-value means the comparison of each session with the first one that is the reference. The improvement is how much the benchmark value (baseline) increases. For example, the variable Attention in session 3 increased $83.3 \%$ over session 1 (baseline) and in session 12 the increase was $350.0 \%$.

The overall improvement of the four variables studied (Attention, Happiness, Relaxation and Respect turn) was statistically significant $(\mathrm{p}<0.001)$. If we detail the improvement in each of the sessions analyzed, a significant improvement can be observed in all of them except in session 3 of the Relaxation variable $(\mathrm{p}=0.317)$ (Table 6).

Table 6. Score for each session and comparison with session 1 (baseline)

\begin{tabular}{|c|c|c|c|c|}
\hline & $\mathbf{N}$ & mean \pm SD & $\mathbf{p}^{*}$ & Improvement** \\
\hline Attention - S1 & 12 & $0.5 \pm 0.7$ & & \\
\hline Attention - S3 & 12 & $0.9 \pm 0.7$ & 0.025 & $83.3 \%$ \\
\hline Attention - S5 & 12 & $1.4 \pm 0.8$ & 0.001 & $183.3 \%$ \\
\hline Attention - S8 & 12 & $1.8 \pm 0.7$ & 0.001 & $266.7 \%$ \\
\hline Attention - S10 & 12 & $2.3 \pm 0.9$ & 0.002 & $350.0 \%$ \\
\hline Attention - S12 & 12 & $2.3 \pm 0.9$ & 0.002 & $350.0 \%$ \\
\hline \multirow[t]{2}{*}{ Global } & & & $<0.001$ & \\
\hline & $\mathbf{N}$ & mean \pm SD & $\mathbf{p}^{*}$ & Improvement** \\
\hline Happiness - S1 & 12 & $1 \pm 0.7$ & & \\
\hline Happiness - S3 & 12 & $1.3 \pm 1$ & 0.046 & 33.3 \\
\hline Happiness - S5 & 12 & $1.6 \pm 0.9$ & 0.008 & $58.3 \%$ \\
\hline Happiness - S8 & 12 & $1.9 \pm 0.9$ & 0.002 & $91.7 \%$ \\
\hline Happiness - S10 & 12 & $2.3 \pm 0.8$ & 0.001 & $133.3 \%$ \\
\hline Happiness - S12 & 12 & $2.4 \pm 0.8$ & 0.002 & $141.7 \%$ \\
\hline \multirow[t]{2}{*}{ Global } & & & $<0.001$ & \\
\hline & $\mathbf{N}$ & mean \pm SD & $\mathbf{p}^{*}$ & Improvement** \\
\hline Relaxation - S1 & 12 & $1.3 \pm 0.8$ & & \\
\hline Relaxation - S3 & 12 & $1.4 \pm 0.8$ & 0.317 & $6.3 \%$ \\
\hline Relaxation - S5 & 12 & $1.8 \pm 0.8$ & 0.034 & $37.5 \%$ \\
\hline Relaxation - S8 & 12 & $2.1 \pm 0.5$ & 0.007 & $56.3 \%$ \\
\hline Relaxation - S10 & 12 & $2.5 \pm 0.7$ & 0.006 & $87.5 \%$ \\
\hline Relaxation - S12 & 12 & $2.5 \pm 0.7$ & 0.030 & $100.0 \%$ \\
\hline \multirow[t]{2}{*}{ Global } & & & $<0.001$ & \\
\hline & $\mathbf{N}$ & mean \pm SD & $\mathbf{p}^{*}$ & Improvement** \\
\hline Respect the waiting time - S1 & 12 & $0 \pm 0$ & & n.a. \\
\hline Respect the waiting time - S3 & 12 & $0.8 \pm 0.5$ & 0.003 & n.a. \\
\hline Respect the waiting time - S5 & 12 & $2 \pm 0.7$ & 0.002 & n.a. \\
\hline Respect the waiting time - S8 & 12 & $2.6 \pm 0.5$ & 0.002 & n.a. \\
\hline Respect the waiting time - S10 & 12 & $2.8 \pm 0.5$ & 0.001 & n.a. \\
\hline Respect the waiting time - S12 & 12 & $2.8 \pm 0.4$ & 0.001 & n.a. \\
\hline Global & & & $<0.001$ & \\
\hline
\end{tabular}

*: Wilcoxon paired test for each sessions vs. session 1. Global test is a Friedman paired test to contrast whether the assessment is equal in all the sessions.

**: Improve is the result of the assessment of each session minus the assessment in the first session divided by the first session assessment, therefore the perceptual increase in each session. n.a.: Not applicable 
Figure 1 shows how each variable evolves in each session graphically; all the variables ascend progressively, evidencing the progressive improvement of the results. The difference is that the variables Attention and Respect turn ascend faster than the rest, resulting in better results being obtained faster.
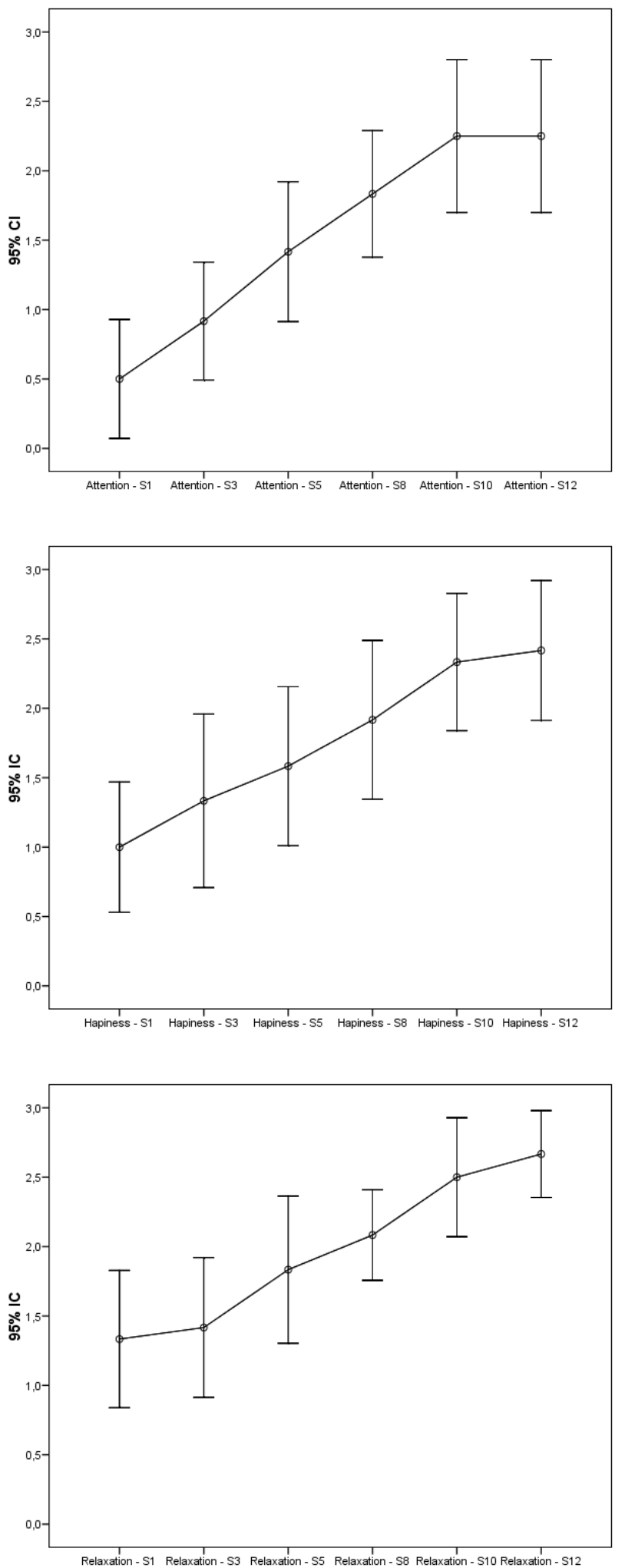

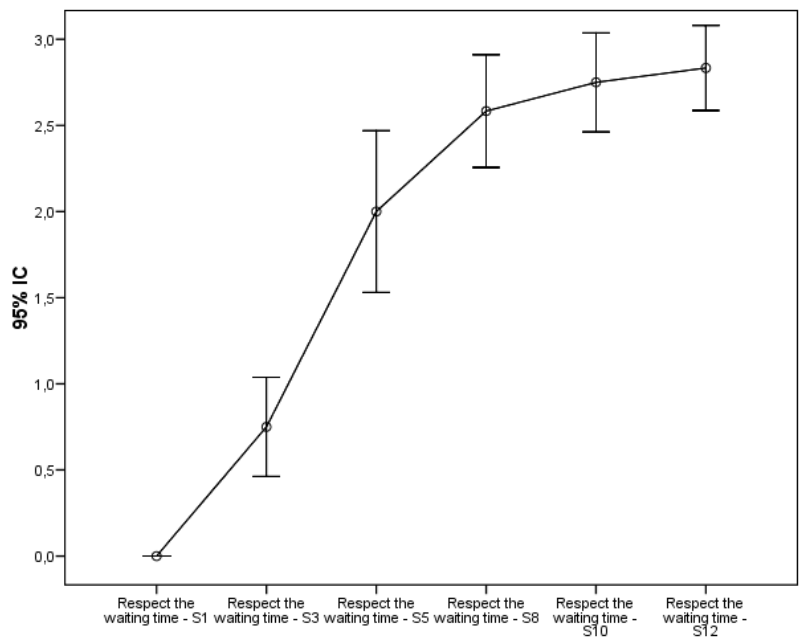

Figure 1. Evolution of each parameter in each session

\section{Discussion}

There is increasing evidence that animals contribute significantly to the psychological well-being of people [15]. In our study throughout the sessions it was possible to establish a working dynamic that favored a progressive improvement in attention and respect for waiting times, demonstrating a high motivation for the sessions performed with the dogs. In fact, in 1962 Boris Levinson [19], a Canadian child psychiatrist and pioneer in animal-assisted therapy, already provided reports on the effectiveness of AAT with children, highlighting the particular benefit of the presence of a dog in inhibited, autistic, non-verbal or introverted and uncommunicative children.

Many children have natural affinity for dogs and can be captivated by this animal, achieving strong emotional attachments that contribute to their development and quality of life [18]. Calm and well-trained therapy dogs offer a unique form of social and emotional support in educational and therapeutic settings [20] and invite peer interaction [13]. Research shows that working with therapy dogs can contribute to motivation, maintain attention and increase persistence in tasks, even when other interventions have failed [11].

During these AAT sessions we have observed that happiness, pleasure and relaxation remain at high levels, as in previous studies where the presence of the animal improves the perception of the level of anxiety, tolerating and having a better response to stressful situations [21].

In this study, the evolution has been positive in all items assessed, resulting in more rapid improvements in attention and respect of waiting times. The variables of happiness and relaxation have had a more progressive evolution.

If we compared the results of each variable obtained in each session evaluated, with the baseline value of the first day, we obtained in all, an improvement that was 
statistically significant except in the relaxation variable where the evolution was slower and the improvement was not significant until session 5. This may be due to the excitement involved in the presence of the animal, which was a new and unusual experience in the school environment. This same effect was obtained in a study that investigated the response to the presence of dogs with children diagnosed with Attention Deficit and Hyperactivity Disorder, where it was found that after interacting with the dog, blood pressure and heart rate suggested an effect of excitement on the children more than a soothing effect by the animal [22]. Possibly this effect can be attributed to the fact of not including a period of habituation to the animal. Therefore, the children had an unknown dog for 5 minutes in each of the two test sessions and were not given any instruction on how to interact with the dog. In contrast, in our study the interaction between the children and dogs was always supervised by the AAI technician.

There is increasing evidence of the positive effects that pets, particularly dogs, can have on children's behavior. Working with animals is remarkably effective with children who have attention difficulties and disruptive behaviors [11]. According to Calvo et al. [23], AAT could be a beneficial intervention for children with behavioral and emotional problems, in terms of program adherence and behavioral improvement.

Regarding the attention variable in the first session, 58.3\% of the participants obtained a score of 0 meaning they never paid attention. However, in the last session (12) none of them scored 0 and $50 \%$ reached the maximum attention score (3). As defined by Ching [24], the effectiveness of the presence of a dog in the sessions' results in increased smiles, attention, conversation, increases the frequency and duration of positive behaviors and social skills.

The happiness and relaxation variables that best reflect the emotional well-being of the participants, obtained a progressive improvement, achieving in the last session the maximum score of $58.3 \%$ in manifestations of happiness and $66.7 \%$ in relaxation. In this regard other authors have studied at a physiological level the possible relaxing effects of interacting with dogs. It has been shown that the presence of a dog reduces blood pressure, heart rate and other signs of anxiety [11]. Increased oxytocin production, decreased levels of cortisol, blood pressure and galvanic skin measurements found in research on the effects of man-animal interactions quantify the physiological effect of stress reduction and anxiety in humans $[25,26]$.

According to Kolrschal and Ortbauer [9], dogs have a positive influence on the social behavior of schoolchildren, making them socially more uniform due to the decrease in the extremes of behaviors such as aggressiveness and hyperactivity. They conclude that the presence of a dog in a classroom can positively stimulate the social cohesion of children. In none of the studies reviewed have we found that respect for waiting times has been evaluated, an important aspect for an appropriate working dynamic in the classroom, since it favors respect for peers and group cohesion as reported by other authors [9]. As for the variable to respect waiting times to participate in activities, no participant respected their turn $(100 \%)$ in the first session. However, in the last session the majority (83.3\%) obtained the maximum score, always respecting the waiting times.

One of the limitations of our study was the size of the sample, although it was sufficient to be able to see an evolution throughout the sessions. The literature reviewed in the school field shows how other authors who have studied the effect of the presence of a dog in the classroom also did so with small samples. Anderson and Olson [27] analyzed how a therapy dog in a class of six children affected by severe emotional disorders were positively influenced in emotional stability and learning. In the observational study by Esteves and Stokes [28], three children with developmental disorders participated, and by means of video recording they evaluated the social interactions of children towards their teacher and towards the dog in the school. Limond, Bradshaw, and Cormack [29] also conducted a study to evaluate the effect of a dog on eight children with severe learning difficulties and diagnosed with Down Syndrome. They compared the interaction of children with a real dog and a toy dog. The children became more attentive to the dog and to the adult when the dog was real.

In the study of Anderson and Olson [27] the presence of the dog in the class was during a period of 8 weeks and no standardized measures were collected, which could imply a potential bias in the interpretation of the results obtained by the teacher/researcher; in our study the continuous assessment scale used is not standardized, thus bringing about another limitation. Although the tests have not been validated in a formal way those were designed as a likert scale, lower values indicating lower agreement. The low number of patients recommended the use of non-parametric test and although the design of the study is quantitative for this sample size it could be important to introduce a qualitative approach. Despite this, the observation and interpretation of the results was always performed by the same person (Primary Care Center nurse trained for this research).

Another limitation was not having a parallel control group; given the difficulty in finding groups that are uniform and comparable to each other, due to the particularities of each participant. In addition, quantitative methodology could mean a limitation in the obtained results, which is why applying qualitative methods in future research could be worthwhile; like other authors have done [28] where the qualitative evaluation showed widespread improvements in the interactions of the children with the teacher in the classroom after the sessions with the dog. The evaluation of the generalization of the effect obtained in the sessions with the therapy dog and its 
maintenance in the long term would be an interesting aspect for future research.

In a recent systematic review, the authors refer to variability in sample size and duration of time exposed to an animal [17]; with interventions ranging from 4 to 24 weeks of duration, with three minutes of direct interaction until the dog is present all day in the classroom. Our intervention period was 12 weeks and the sessions with the dog were an hour in duration because it was considered the best option for the dog's welfare.

The teachers who participated in the project expressed their satisfaction about the intervention that was carried out; coinciding with the 75 primary teachers in Daly and Suggs's study [30], who considered that the use of companion animals in the classroom contributed positively to greater empathy and socio-emotional development of the students. And a survey of 1,400 teachers showed that nearly $70 \%$ used animals in the classroom, with improvements in attention, motivation, mood and well-being, social-emotional development and empathy as well as the cognitive development of the children [31].

Systematic reviews of the literature have been conducted to examine the impact of AAI on the health and well-being of children and adolescents [32-35], and despite the positive results obtained by different authors; criticisms persist with regard to the methodology used and the shortage of protocols. In our study the whole intervention was planned in advance and strict animal welfare and zoonosis prevention protocols were followed. Although the objective of providing more scientific evidence on the benefits of AAI has generated the need for further research with more controlled designs, larger samples and with qualitative and quantitative methodology; as well as, perform the observation and review of the results with two observers.

After conducting this study, with the results obtained and, like other authors [36], we believe that animal-assisted interventions can be useful as complementary programs to improve the functional autonomy, emotional well-being and quality of life of people with special needs. A dog in the classroom has positive emotional effects such as bonding, providing an alternative focus of attention, distraction to anger, social facilitator by improving interactions with teachers, family members or peers, providing lessons of respect, responsibility, and empathy [27].

\section{Conclusions}

The inclusion of animals in educational practice is increasingly popular [17]. The focus of the research in many of the reviewed studies was largely socio-emotional, including the effect of animals on mood, emotional regulation, social behaviors and general behavior in the classroom; as well as adherence to and follow-up of instructions issued by teachers [27,37]

The happiness and relaxation variables that best reflect the emotional well-being of the participants, obtained a progressive improvement, achieving maximum scores in the last session in more than $50 \%$ of the participants. A similar effect, although somewhat lower was obtained in the attention variable. The ability to focus and maintain attention is critical to learning; dogs constitute a center of attention and the therapist can approach the child through the animal [19]. Therapy dogs promote the autonomy of schoolchildren; children learned to pay attention to the needs of others and take responsibility for their welfare [10]; and as we have found in our study, to respect the waiting times when it was necessary and to improve the work dynamic in the classroom.

The results of this study support that animal-assisted therapy can help children with intellectual disabilities and behavior disorders, improving their emotional well-being, with the dog acting as a therapy facilitator. Primary Health Care can contribute to improving the quality of life of children with special needs and at risk of social exclusion by means of community interventions. As a result, Animal-Assisted Therapy is a valid option and should be kept in mind as a complementary resource that can facilitate many of the community interventions that we carry out.

\section{Acknowledgements}

We are grateful to the management and professional staff at the Bordeta-Magraners Primary Care Center in Lleida and to the IDIAP Jordi Gol Research Support Unit for facilitating the realization of this study; to the Ilerkan Association for providing the therapy dogs; and to the special education school Esperança de Lleida.

\section{Appendix 1: Sessions}

\section{Session 1: "We make friends"}

\section{Objectives:}

- Present a new activity.

- Work on social skills and stimulate communication.

- Stimulate memory.

- $\quad$ Promote a group activity and teamwork.

- Work on psychomotricity and motor coordination.

- Respect turn-taking.

\section{Session procedure:}

Start routine and assign roles: we say hello and the session begins with us introducing ourselves. We let each child say hello and touch the dogs individually to build trust. 
We explain the tasks that have to be done to take care of the dogs (put on their collars and work harness, give them water, brush them, rewards, balls, etc.); we ask them to help us look after the dogs and we assign a task to each child.

\section{Exercise 1}

We present each dog, say its name and tell its biography. We ask each child to present his/her dog likewise. The objective is to be able to go over the dog's lives on subsequent days to stimulate memory.

\section{Exercise 2}

Set up an obstacle course together, with hoops, cones, fences and the tunnel laid out around the room to simulate an "agility course".

Have the dogs pass through or over the obstacles with the child holding the dog.

Goodbye routine: We throw a ball to the dogs and the dogs have to return it, taking turns.

Materials: Hoops, cones, fences, a tunnel, balls.

\section{Session 2: "Handkerchief memory game"}

\section{Objectives:}

- Strengthening the ability to make choices and self-esteem.

- Work on memory and strengthen attention span.

- Respect turn-taking and waiting.

- Improve the body scheme and lateral awareness (handedness)

- Work on fine motricity.

\section{Session procedure:}

1. Start routine.

2. We will have a bag full of different colored handkerchiefs. The children come out in pairs, one of them will put the handkerchiefs on one of the dogs (on the neck, paws and tail) and the other will have to memorize the distribution of the handkerchiefs and do the same with the other dog. The rest of the group will help to decide if they are placed correctly. We will reward them with the same number of prizes as the number of correct handkerchiefs; the dog can then be asked to perform the tricks the children choose (number of tricks $=$ number of prizes they have won).

3. We play basketball with the dog.

4. Goodbye routine.

Materials: colored handkerchiefs, basketball net and ball.

\section{Session 3: "Let's play the imitation game"}

\section{Objectives:}

- Work on coordination and psychomotricity.
- $\quad$ Stimulate the ability to imitate.

- Strengthen attention span and memory.

- Enhance spontaneity and the ability to make choices.

\section{Session procedure:}

Start routine and assignment of tasks.

We stand upright in a circle, first with the dog in the center. We will have to imitate everything the dog does, sit, lie down, take a bow, roll over, shake paws (legs), put a hoop around its neck, etc.

Next a child will go into the middle of the circle with the dog and everyone (including the dog) will imitate whatever the child does.

\section{Exercise 2:}

We will pick up a bag with three of the dog's toys, which we will have to recall.

The dog takes one of the toys and hides it; the children have to say which one is missing.

Goodbye routine.

Materials: 3 toys for dogs and a bag.

\section{Session 4: "Let's match up the socks"}

\section{Objectives:}

- Recognizing colors and sizes.

- Strengthening and stimulating attention.

- Following a sequence.

- Turn-taking.

- Ability to make choices.

\section{Session procedure:}

Start routine (assign and perform tasks).

Recognize colors and patterns of different socks.

In the first exercise a sock will be on the ground and the matching sock will be hanging from a string with a peg; the dogs will bring them the sock from the ground that will have to match the one hanging from the string.

In the second exercise, all of the socks will be on the ground and the dog will bring them one by one to each child. The users who have the matching sock will have to put them side by side.

Once all of the matching pairs have been made, each pair will ask the dog to do the trick they most enjoy (they will have to reach an agreement on this and choose one together).

When the dog brings a sock, the child will give the dog a reward.

Goodbye routine. 
Materials: Various differently-colored socks, flexible string and pegs and prizes for the dog.

\section{Session 5: "Let's find differences between dogs and us" \\ Objectives:}

- Work on lateral awareness and body scheme.

- Foster awareness of one's own body.

- Stimulate attention when looking for similarities and differences.

- Work on memory.

\section{Session procedure:}

1. Start routine and assignment of tasks.

2. Each participant names a part of their body (each child a different part); then we ask which part the other classmate said, to work on memory and attention.

1. It is important to foster the use of the terms "left" and "right"; observe that we have two sides (2 arms, 2 ears, 2 eyes, etc.).

2. We form a circle with the dogs in the middle; every child has to look for the part of the body that he/she said in the dogs and identify their similarities and differences.

3. We can take the opportunity to describe the sensation when touching parts of the animal (skin, nails, nose, etc.).

4. We will play football with the dog (the dog will be the goalkeeper).

5. Goodbye routine.

Materials: Cones and a football.

\section{Session 6: "Playing as a team"}

\section{Objectives:}

- Boost physical exercise.

- Work on dynamic coordination and balance.

- Foster teamwork.

- Recognize colors.

- $\quad$ Respect turn-taking and waiting.

\section{Session procedure:}

Start routine and assignment of tasks.

We set up two groups of children; each group will have one dog.

At the other end of the room we will leave two hoops full of balls of different colors.

Each child accompanied by the dog will have to run to look for a ball and bring it back to where the others are, then the child hands over the dog to the next child on his/her team who in turn does the same and so on, as a relay race.

The winning team is the one that brings back all of the balls first.

The activity can be repeated moving backwards or sideways.

End the session counting and recognizing the colors of the balls and throwing them to the dog.

Goodbye routine.

Materials: Colored hoops and balls.

\section{Session 7: "Let's play at identifying objects"}

\section{Objectives:}

- Stimulate the sense of touch.

- Recognize different objects.

- Strengthen communication and conversation.

- Physical exercise.

- $\quad$ Respect turn-taking and waiting.

\section{Session procedure:}

1. Start routine.

2. The dog will bring them an everyday object (toothbrush, glass, spoon, fork, shoe, cushion, napkin, water bottle, watch, etc.) and the dog's own objects (collar, brush, ball, mitten, etc.) and they will have to identify and describe them with their eyes closed.

3. Form a tunnel with legs for the dog to pass through.

4. Goodbye routine.

Materials: various objects.

\section{Session 8: "Making pairs"}

\section{Objectives:}

- Working on the cognitive level: comprehension and recognition of images.

- Abstract thought.

- Attention and memory.

- Respect turn-taking and waiting.

\section{Session procedure:}

Start routine and assignment of tasks.

We have different flashcards on the floor with drawings or photographs of objects.

\section{Exercise 1}

The dog brings them a flashcard and they have to identify the drawing and look for the matching card (e.g. knife and fork, sock and shoe, pencil and paper, gloves and scarf, rain and umbrella, etc.). We ask them to explain why they think the cards form a matching pair.

\section{Exercise 2}

In pairs, the children will go to the middle of the room and 
they will get the dog to do a trick (bow, greeting, twist, paw, etc.).

Goodbye routine.

Materials: Flashcards with drawings or photographs.

\section{Session 9: "Number carpet"}

\section{Objectives:}

- Improve attention and memory.

- Exercise fine motricity.

- Recognize numbers and form pairs of matching shapes.

- Follow the numerical series.

\section{Session procedure:}

1. Start routine and assignment of tasks.

2. Independent learning activity: We will lay out outlines of numbers on the table. The dog will bring them a number from the floor that they will have to identify and say the colour. Once the number has been identified, they will have to look for the outline that matches it and place it. We ask them to put them in order from large to small.

3. Fun activity: We will hide food as part of a game in which the dogs will use their sense of smell.

4. Goodbye routine (combing and stroking the dog, giving it rewards and saying goodbye).

Materials: Number carpet and dogs' follow the scent game.

\section{Session 10: "Let's sort the toys"}

\section{Objectives:}

- Cognitive stimulation.

- Work on the recognition and categorization of objects.

- Improve attention and concentration.

- $\quad$ Respect turn-taking and waiting.

- Stimulate the ability to make choices.

\section{Session procedure:}

1. Start routine and assignment of tasks.

2. Independent learning activity: We will have a basket on the floor with rubber animals and plastic fruit. Each child in turn will ask the dog to bring him/her an object from the basket. The child will have to recognize the object and say if it is an animal or a fruit. We will take the opportunity to ask about the color and if it is an animal, what sound it makes.

3. Fun activity: We will set up a hoop of colors through which we will make the dogs jump and finish by forming a tunnel of hoops through which the dogs will pass.
4. Goodbye routine (combing and stroking the dog, giving it rewards and saying goodbye).

Materials: A basket, some rubber or plastic animals and fruits; a collapsible circle and a multi-colored hoop.

\section{Session 11: "Geometric shapes"}

\section{Objectives:}

- Cognitive level: comprehension and recognition of shapes.

- Recognizing colors.

- Making pairs.

- Stimulate attention.

- Respect turn-taking and waiting.

\section{Session procedure:}

1. Start routine and assignment of tasks.

2. Independent learning activity: We will have flashcards with several geometric shapes (triangles, circles and squares) in various colors: yellow, green, blue and red (two of each). We will have one card from each pair on the table and the other on the floor so that the dog will deliver it to them. When the dog gives them the card, they will have to recognize the color, the geometric shape and look for the matching card. We will draw a triangle, a circle and a square on the clover.

3. Fun activity: We play football with the dog. The dog will be the goalkeeper and the children will take turns kicking the ball lining up one behind the other (respecting turns).

4. Goodbye routine (combing and stroking the dog, giving it rewards and saying goodbye).

\section{Materials:}

Cards made to fit the dog with different geometric shapes, paper and colors for drawing, 2 cones for goal posts and a ball.

Session 12: "We say goodbye with a party"

\section{Objectives:}

- Stimulate creativity.

- Work on fine motricity.

- Stimulate the ability to make choices.

- Foster teamwork.

\section{Session procedure:}

1. Start routine and assignment of tasks.

2. Independent learning activity: We will have self-adhesive paper bags with which we can make a cow costume for each child. First, they will have to draw and cut out the pieces that will stick to the bags to make the costume. We will make horns using sheets of EVA artificial rubber which we will staple to a cardboard strip for each child. 
3. Fun activity: Working together, we make the same costume for the dog.

4. We take souvenir photographs.

5. Goodbye routine (combing and stroking the dog, giving it rewards and saying goodbye). We say goodbye to the dogs.

Materials: Miscellaneous materials needed to make the costume.

\section{REFERENCES}

[1] Institut Català de la Salut Atenció Primària Lleida. Generalitat de Catalunya. Available online at: http://www.icslleida.cat/primaria/

[2] S. Bonet, I. Pérez, T. Torres, N. Ventura. PC City. Una proposta de criteris tècnics per a l'acció comunitària de serveis socials bàsics de Barcelona. Març 2009.

[3] I. García. Promoción de la salud en el medio escolar. Revista española de Salud pública, vol. 72, No. 4, 285-287, 1998.

[4] F. Martin, J. Farnum. Animal-assisted therapy for children with pervasive developmental disorders. Western Journal of Nursing Research, Vol. 24, No. 6, 657-70, 2002.

[5] F. Ristol, E. Domènec. Terapia Asistida con Animales. II Manual práctico pata técnicos y expertos. CTAC: Barcelona, 2012.

[6] IAHAIO. White paper 2014. The IAHAIO definitions for animal assisted intervention and guidelines for wellness of animals involved. International Human-Animal Interaction Organizations. Available online at:

http://iahaio.org/new/fileuploads/9313IAHAIO\%20WHITE \%20PAPER \%20TASK\%20FORCE\%20-\%20FINAL\%20R EPORT.pdf

[7] R. Martínez Abellan. La terapia asistida por animales: una nueva perspectiva y línea de investigación en la atención a la diversidad. Indivisa, Bololetín de Estudios e Investigación, Vol. 9, 117-44, 2008.

[8] R. N. Gee, S. L. Harris, K. L. Johnson. The Role of Therapy Dogs in Speed and Accuracy to Complete Motor Skills Tasks for Preschool Children, Anthrozoös, Vol. 20, No. 4, 375-386, 2007.

[9] K. Kotrschal, B. Ortbauer. Behavioral effects of the presence of a dog in a classroom, Anthrozoös, Vol. 16, No. 2, 147-159, 2003.

[10] A. Hergovich, B. Monshi, G. Semmler, V. Zieglmayer. The effects of the presence of a dog in the classroom. Anthrozoös, Vol. 15, No. 1, 37-50, 2002.

[11] M. R. Jalongo. What are all these Dogs Doing at School? Using Therapy Dogs to Promote Children's Reading Practice. Childhood Education, Vol. 81, No. 3, 152-158, 2005.

[12] N. R. Gee, J. M. Belcher, J. L. Grabski, M. DeJesus, W. Riley. The presence of a therapy dog results in improved object recognition performance in preschool children.
Anthrozoös, Vol. 25, 289-300, 2012.

[13] A. M. Beck, A. H. Katcher. Future directions in human-animal bond research. American Behavioral Scientist, Vol. 47, No. 1, 79-93, 2003.

[14] S. S. Hall, N. R. Gee, D. S. Mills. Children reading to dogs: A systematic review of the literature. PLoS ONE, Vol. 11,2, 2016.

[15] S. M. Rabbitt, A. E. Kazdin, J. E. Hong. Acceptability of Animal-Assisted Therapy: Attitudes toward AAT, Psychotherapy, and Medication for the Treatment of Child Disruptive Behavioural Problems, Anthrozoös, Vol. 27, No. 3, 335-350, 2014.

[16] R. Martos-Montes, D. Ordóñez-Pérez, I. De la Fuente-Hidalgo, R. Martos-Luque, M. R. García-Viedma. Intervención asistida con animales (AAI): Análisis de la situación en España. Escritos de Psicología, Vol. 8, No. 3, $1-10,2015$.

[17] V. L. Brelsford, K. Meints, N. R. Gee, K. Pfeffer. Animal-Assisted Interventions in the Classroom-A Systematic Review. International Journal of Environmental Research and Public Health, Vol. 14, 669, 2017.

[18] R. L. Zasloff, L. A. Hart, H. DeArmond. Animals in Elementary School Education in California, Journal of Applied Animal Welfare Science, Vol. 2, No. 4, 347-357, 1999.

[19] B. M. Levinson. The dog as "co-therapist." Mental Hygiene, Vol. 46, 59-65, 1962.

[20] L. Friesen. Exploring Animal-Assisted Programs with Children in School and Therapeutic Contexts. Early Childhood Journal. Vol. 37, No. 4, 261-267. 2010.

[21] J. S. Young. Pet therapy: dogs de-stress students. Journal of Christian Nursing. Vol. 29, No. 4,217-21, 2012.

[22] Somervill, J. W., Swanson, A. M., Robertson, R. L., Arnett, M. A., MacLin, O. H. Handling a dog by children with attention-deficit/hyperactivity disorder: calming or exciting? North American Journal of Psychology. 2009; 11(1): 111120.

[23] P. Calvo, S. Pairet, M. Vila, J. Losada, J. Bowen, R. Cirac, A. Bulbena, A. Holloway, J. Fatjó. Dog assisted therapy for teenagers with emotional and behavioural issues: A multicentre study. European Psychiatry, Vol. 41, Suppl. April, S432-S433, 2017.

[24] S. Ching Mey. Animal Assisted Therapy for children with autism. International Journal of child development and mental Health, Vol.5, No. 1 August-January: 29-42, 2017.

[25] M. E. O'Haire, S. J. McKenzie, A. M. Beck, V. Slaughter. Animals may act as social buffers: Skin conductance arousal in children with Autism Spectrum Disorder in a social context. Developmental Psychobiology, Vol. 57, 584-595, 2015.

[26] M. Heinrichs, T. Baumgartner, C. Kirschbaum, U. Ehlert. Social support ad oxytocin interacts to suppress cortisol and subjective responses in psychosocial stress. Biological Psychiatry, 54, 1389-1398, 2003.

[27] K. L. Anderson, M. R. Olson. The value of a dog in a 
classroom of children with severe emotional disorders, Anthrozoös, Vol. 19, No. 1, 35-49, 2006.

[28] S. W. Esteves, T. Stokes. Social Effects of a Dog's Presence on Children with Disabilities, Anthrozoös, Vol. 21, No. 1, $5-15,2008$.

[29] J. A. Limond, J. W.S. Bradshaw, M. K. F. Cormack. Behavior of Children with Learning Disabilities Interacting with a Therapy Dog, Anthrozoös, Vol. 10, No. 2-3, 84-89, 1997.

[30] B. Daly, S. Suggs. Teachers' experiences with humane educational and animals in the elementary classroom: implications for empathy development. Journal of Moral Education. Vol. 39, 1, 2010.

[31] N. R. Gee, A. Fine, S. Schuck. Animals in educational settings: Research and practice. In Handbook of Animal-Assisted Therapy, 4th ed.; Fine, A.H., Ed.; Academic Press: London, UK, 2015.

[32] A. Maujean, C. A. Pepping, E. Kendall. A systematic review of randomized controlled trials of animal-assisted therapy on psychosocial outcomes. Anthrozoös, Vol. 28, 23-36, 2015.
[33] C. Busch, L. Tucha, A. Talarovicova, A.B.M. Fuermaier. Animal-assisted interventions for children with attention deficit/hyperactivity: A theoretical review and consideration of future directions. Psychological. Reports, Vol. 118, 1, 2016.

[34] H. Kamioka, S. Okada, K. Tsutani, H. Park, H. Okuizuma, S. Handa, T. Oshia, S. Park, J. Kitayuguchi, T. Abe, et al. Effectiveness of animal-assisted therapy: A systematic review of randomized controlled trials. Complementary Therapies in Medicine, Vol. 22, 371-390, 2014

[35] K. E. Hoagwood, M. Acri, M. Morrissey, R. Peth-Pierce. Animal-assisted therapies for youth with or at risk for mental health problems: A systemic review. Applied Developmental Science, Vol. 21, 1-13, 2016.

[36] S. Muñoz Lasa, G. Ferriero, E. Brigatti, R. Valero, F. Franchignoni. Animal-assisted interventions in internal and rehabilitation medicine: a review of the recent literature. Panminerva Medicine., Vol. 53, No. 2, 129-36, 2011.

[37] A. Beetz. Socio-emotional correlates of a school-dog-teacher team in the classroom. Frontiers in Psychology, Vol. 4, 886, 2013. 